\title{
AChR deficiency due to $\varepsilon$-subunit mutations: two common mutations in the Netherlands
}

\author{
Catharina G. Faber $\cdot$ Peter C. Molenaar $\cdot$ Johannes S. H. Vles • \\ Domenic M. Bonifati - Jan J. G. M. Verschuuren - Pieter A. van Doorn · \\ Jan B. M. Kuks · John H. J. Wokke · David Beeson · Marc De Baets
}

Received: 9 February 2009/Revised: 23 April 2009/ Accepted: 18 May 2009/Published online: 21 June 2009

(C) The Author(s) 2009. This article is published with open access at Springerlink.com

\begin{abstract}
Congenital myasthenic syndromes are a clinically and genetically heterogeneous group of hereditary disorders affecting neuromuscular transmission. We have identified mutations within the acetylcholine receptor (AChR) $\varepsilon$-subunit gene underlying congenital myasthenic syndromes in nine patients (seven kinships) of Dutch origin. Previously reported mutations $\varepsilon 1369 \mathrm{delG}$ and $\varepsilon$ R311Q were found to be common; $81369 \mathrm{delG}$ was present on at least one allele in seven of the nine patients, and $8 \mathrm{R} 311 \mathrm{Q}$ in six. Phenotypes ranged from relatively mild ptosis and
\end{abstract}

Electronic supplementary material The online version of this article (doi:10.1007/s00415-009-5190-7) contains supplementary material, which is available to authorized users.

\section{G. Faber $(\bowtie)$}

Department of Neurology,

Maastricht University Medical Centre,

PO Box 5800, 6202 AZ Maastricht, The Netherlands

e-mail: c.faber@mumc.nl

P. C. Molenaar

Department of Neurophysiology and Molecular Cell Biology, Leiden University Medical Center,

Leiden, The Netherlands

\section{J. S. H. Vles}

Department of Child Neurology,

Maastricht University Medical Centre,

Maastricht, The Netherlands

D. M. Bonifati · D. Beeson

Neuroscience Group,

Weatherall Institute of Molecular Medicine,

The John Radcliffe, Oxford, UK

\section{J. J. G. M. Verschuuren}

Department of Neurology,

Leiden University Medical Center, Leiden,

The Netherlands external ophthalmoplegia to generalized myasthenia. The common occurrence of $\varepsilon \mathrm{R} 311 \mathrm{Q}$ and $\varepsilon 1369 \mathrm{delG}$ suggests a possible founder for each of these mutations originating in North Western Europe, possibly in Holland. Knowledge of the ethnic or geographic origin within Europe of AChR deficiency patients can help in targeting genetic screening and it may be possible to provide a rapid genetic diagnosis for patients of Dutch origin by screening first for $\varepsilon \mathrm{R} 311 \mathrm{Q}$ and $\varepsilon 1369 \mathrm{delG}$.

Keywords Congenital myasthenic syndrome · AChR $\varepsilon$-subunit gene $\cdot$ AChR mutations

\author{
P. A. van Doorn \\ Department of Neurology, \\ Erasmus Medical Center, \\ Rotterdam, The Netherlands \\ J. B. M. Kuks \\ Department of Neurology, \\ University Medical Centre Groningen, \\ Groningen, The Netherlands \\ J. H. J. Wokke \\ Department of Neurology, \\ University Medical Center Utrecht, \\ Utrecht, The Netherlands \\ P. C. Molenaar - M. De Baets \\ Department of Neuroscience, \\ Institute of Mental Health and Neuroscience, \\ Maastricht University Medical Centre, \\ Maastricht, The Netherlands
}




$\begin{array}{ll}\text { Abbreviations } \\ \alpha \text {-BuTx } & { }^{125} \mathrm{I}-\alpha \text {-Bungarotoxin } \\ \text { AChR } & \text { Acetylcholine receptor } \\ \text { CHRNE } & \text { AChR } \varepsilon \text {-subunit gene } \\ \text { CMS } & \text { Congenital myasthenic syndrome } \\ \text { PCR } & \text { Polymerase chain reaction }\end{array}$

\section{Introduction}

The congenital myasthenic syndromes (CMSs) are a group of hereditary disorders affecting neuromuscular transmission [1-3]. The disorders are clinically and genetically heterogeneous [4]. Patients frequently present at birth or within the first two years of life. Most present with ocular, bulbar or respiratory muscle symptoms, worsened by crying or activity. The majority of CMSs primarily affect postsynaptic function, and are caused by mutations in subunits of the acetylcholine receptor (AChR), in the AChR-clustering protein rapsyn, or in DOK7. The AChR mutations may alter kinetic properties (slow- and fast-channel syndromes), decrease expression of the AChR pentamer (AChR deficiency) [5] or alter kinetic properties and decrease expression. Many mutations that decrease $\mathrm{AChR}$ expression reside in the $\mathrm{AChR} \varepsilon$-subunit gene [6], with the resulting AChR deficiency phenotype inherited as an autosomal-recessive trait $[3,5,7]$.

CMSs are relatively rare disorders that may be difficult to diagnose in infants and early childhood. Many of the AChR $\varepsilon$-subunit gene mutations are restricted to a single or only a few kinships. Consequently, genetic screening for AChR deficiency frequently requires thorough analysis of the whole of the $\varepsilon$-subunit gene. Here we present the cases of nine patients (seven kinships) for whom the diagnosis of congenital myasthenia has recently been confirmed by genetic analysis. We find a common occurrence of mutations $\varepsilon$ R311Q and $\varepsilon 1369 \mathrm{delG}$ in AChR deficiency patients of Dutch origin.

\section{Patients and methods}

We identified nine CMS patients in the Netherlands (Table 1). All patients were of Dutch origin and Caucasian. Patients 3-8 have been reported before by the late Dr. Oosterhuis before mutation analysis was performed [8]. Antibodies to the AChR were absent in all cases. Patients generally presented with ptosis and ophthalmoparesis from infancy or early childhood. Some of them had swallowing difficulties or proximal muscle weakness later on. Neostigmine had a moderate effect in most patients. Some patients remained stable throughout life, whereas others slowly declined in muscle strength.

Patient 1, a 14-year-old boy with non-consanguine parents, presented at the age of two and a half years with ptosis and ophthalmoparesis. The ptosis had been present from birth. He remained stable until the age of 10, when he presented with a rapid progressive weakness involving his arms, legs and bulbar muscles, following a flu-like disease. These symptoms resolved spontaneously after a few days. He improved after administration of neostigmine. Repetitive nerve stimulation showed no decrement of compound muscle action potentials (CMAPs), nor repetitive CMAPs.

Patient 2 is the younger brother of patient 1 , who according to the parents had symptoms of ophthalmoparesis and ptosis at the age of two years. No muscle weakness of arms or legs was noted. His parents did not request further investigations to be made. His current age is 9 years, and he has apparently been stable so far.

Patient 3 had drooping eyelids from early infancy, and was never able to run. At the age of 23 she had ptosis at both eyes, a nearly complete ophthalmoplegia, mild facial weakness and mild weakness of the limbs. She improved after treatment with neostigmine. During the following years her symptoms remained unchanged.

Patient 4 is a 24-year-old man who has had swallowing difficulties from birth. At the time of the biopsy (when he was 5 years old) he had drooping eyelids and difficulties

Table 1 Patients with congenital myasthenic syndrome in the Netherlands and $\varepsilon 1369 \mathrm{delG}$ and/or $\&$ R311Q mutations

\begin{tabular}{|c|c|c|c|c|c|c|c|c|}
\hline $\begin{array}{l}\text { Patient } \\
\text { number }\end{array}$ & $\begin{array}{l}\text { Age at onset } \\
\text { (years) }\end{array}$ & Sex & $\begin{array}{l}\text { Age at diagnosis } \\
\text { (years) }\end{array}$ & $\begin{array}{l}\text { First } \\
\text { symptoms }\end{array}$ & $\begin{array}{l}\text { Actual age } \\
\text { (years) }\end{array}$ & $\begin{array}{l}\text { Actual } \\
\text { symptoms }\end{array}$ & \multicolumn{2}{|c|}{$\begin{array}{l}\text { Mutations found in } \mathrm{AChR} \\
\varepsilon \text {-subunit gene }\end{array}$} \\
\hline 1 & Birth & Male & 2 & $\mathrm{P}$ & 14 & $\mathrm{P}, \mathrm{O}, \mathrm{B}, \mathrm{L}$ & $\varepsilon 1369 \mathrm{delG}$ & $\varepsilon \mathrm{R} 311 \varepsilon \mathrm{R} 311 \mathrm{Q}$ \\
\hline 2 & 2 & Male & 2 & $\mathrm{P}, \mathrm{O}$ & 9 & $\mathrm{P}, \mathrm{O}$ & $\varepsilon 1369 \mathrm{delG}$ & $\varepsilon \mathrm{R} 311 \mathrm{Q}$ \\
\hline 3 & Birth & Female & 7 & $\mathrm{P}$ & 48 & $\mathrm{P}, \mathrm{O}, \mathrm{L}$ & $\varepsilon 1369 \mathrm{delG}$ & $\varepsilon 1369 \mathrm{delG}$ \\
\hline 4 & Birth & Male & 4 & B & 24 & $\mathrm{P}, \mathrm{O}, \mathrm{L}$ & $\varepsilon 1369 \mathrm{delG}$ & $\varepsilon$ 509insA \\
\hline 5 & 1 & Female & 54 & $\mathrm{P}$ & 74 & $\mathrm{P}, \mathrm{O}, \mathrm{L}$ & $\varepsilon 1369 \mathrm{delG}$ & $\varepsilon \mathrm{R} 311 \mathrm{Q}$ \\
\hline 6 & 3 & Male & 38 & $\mathrm{P}$ & 80 & P, O. L & $\varepsilon 1369 \mathrm{delG}$ & $\varepsilon \mathrm{R} 311 \mathrm{Q}$ \\
\hline 7 & Birth & Male & 8 & $\mathrm{P}, \mathrm{B}$ & 38 & $\mathrm{P}, \mathrm{O}, \mathrm{L}$ & $\varepsilon \mathrm{R} 311 \mathrm{Q}$ & $\varepsilon \mathrm{R} 311 \mathrm{Q}$ \\
\hline 8 & Infancy & Male & 18 & B & 32 & $\mathrm{P}, \mathrm{O}, \mathrm{L}$ & $\varepsilon 1369 \mathrm{delG}$ & $\varepsilon \mathrm{Y} 15 \mathrm{H}$ \\
\hline 9 & Infancy & Female & 50 & $\mathrm{P}$ & 53 & $\mathrm{P}, \mathrm{O}, \mathrm{L}$ & $\varepsilon \mathrm{R} 64 \mathrm{X}$ & $\varepsilon \mathrm{R} 311 \mathrm{Q}$ \\
\hline
\end{tabular}

$P$ ptosis, $O$ external ophthalmoplegia, $B$ bulbar symptoms, $L$ limb weakness 
with swallowing. Running with other boys was difficult. Neostigmine, and later mytelase was given from 4 years onwards which provided some improvement. On his last neurologic examination in 2004 he still used neostigmine, with a moderate effect, and his symptoms remained unchanged. Repetitive nerve stimulation showed a decrement of CMAPs.

Patient 5, a 74-year-old woman with unrelated parents, had drooping eyelids from the age of 1 year. Mild generalised weakness especially in arms and hands, impeded her with children's games. At 15 years myasthenia gravis was diagnosed and pyridostigmine was found to have a beneficial effect. Her condition gradually worsened and when she was 51 years old she had diplopia, chewing difficulties and outdoors she became wheelchair dependent. At the time of the biopsy (when she was 58 years old) the muscle bulk was very small, with weakness of the deltoid, arm and leg muscles. The 5th CMAP (3 Hz) of the abductor pollicis brevis showed a $10 \%$ decrement. In the following 17 years the generalised weakness progressed further.

Patient 6, an 80-year-old man (brother of patient 5) had drooping eyelids from early childhood. He had dyspnea after climbing the stairs while he was at primary school. There were no diurnal fluctuations of symptoms, but there were bad days, especially when it was cold. He responded well to treatment with pyridostigmine, which was initiated only when he was 60 years old. At the time of the biopsy (when he was 64 years old) the muscle bulk was small but without obvious atrophy. He could not rise from his chair without the help from his arms. The 5th CMAP (3 Hz) of the abductor digiti minimi muscle showed a $10 \%$ decrement. In the following 20 years the generalised weakness progressed further.

Patient 7 is a 38 -year-old man who had drooping eyelids and weak facial muscles since birth. At the time of the biopsy (when he was 19 years old) he had double vision in the morning, ptosis, and diffuse weakness of the limbs.

Patient 8 is a 32 -year-old man who experienced feeding difficulties due to a weak suck after birth. At the end of his first year he developed drooping eyelids. At the age of 4 years he developed limb weakness. He was never able to stand up without aid of his hand, and could not run. At the age of 18 years he had generalized proximal weakness of his limbs, ptosis, and intermittent diplopia.

Patient 9 is a 53-year-old woman with symmetrical ptosis without double vision since infancy and walking difficulties in childhood. She had to drink with her meals to make swallowing easier. At the age of 50 years she had severe ptosis with very restricted eye movements and sometimes double vision. She is quickly tired in her limbs and is unable to rise from a chair without support. Her fatigue disappeared completely with pyridostigmine.
Genetic analysis

Genomic DNA from patient and control samples was isolated from peripheral blood using the Nucleon ${ }^{\mathrm{TM}}$ II DNA extraction kit (Nucleon Biosciences). Coding exons and regions of the promoter of the $\mathrm{AChR} \varepsilon$-subunit gene were amplified using the polymerase chain reaction (PCR) and amplicons screened for mutations by direct DNA sequencing. DNA changes were confirmed by restriction endonuclease digestion and size fractionation by agarose gel electrophoresis. The detected mutations were not observed in restriction digests of 100 control samples. Functional effects of the missense mutations were confirmed by studies of the mutant AChR expressed in HEK 293 cells [9].

Oligonucleotides 5'-CAAACAGGATATCCAAGGCC ACTAC- $3^{\prime}$ and $5^{\prime}$-CTTCCCCCAAACTCCAGGGAATG GAG- $3^{\prime}$ were used in PCR reactions to amplify a section of the CHRNE $3^{\prime}$ untranslated region that harbours a cluster of SNPs (http://www.ncbi.nlm.nih.gov/SNP/).

Haplotypes were determined by DNA sequence analysis of CMS patients and relatives. Gene frequency for the $\mathrm{G}$ or C nucleotide at SNP rs9914357 was determined by DNA sequencing of 100 control chromosomes. SNPs with minor allele frequency $>25 \%$ (CEPH) were selected.

Data from screening over 100 suspected CMS cases of Northern European origin that did not have CHRNE mutations gave similar allele frequencies to the CEPH population.

\section{Results}

Mutation analysis

Screening of DNA from patients 1-9 identified mutations in the AChR $\varepsilon$-subunit gene (CHRNE). Five different mutations were identified: $\varepsilon \mathrm{Y} 15 \mathrm{H}, \quad \varepsilon \mathrm{R} 64 \mathrm{X}, \quad \varepsilon 509 \mathrm{ins} \mathrm{A}, \varepsilon \mathrm{R} 311 \mathrm{Q}$, ع1369delG. Previous functional studies of these mutations have shown that $\varepsilon \mathrm{R} 311 \mathrm{Q}$ results in severely reduced expression of adult-type AChR with near normal ion-channel properties, whereas $\varepsilon 1369 \mathrm{delG}$ is a null mutation [9]. Four patients (two were siblings) are compound heterozygous for $\varepsilon \mathrm{R} 311 \mathrm{Q} / \varepsilon 1369 \mathrm{delG}$, one is homozygous for $\varepsilon \mathrm{R} 311 \mathrm{Q}$, one homozygous for $\varepsilon 1369 \mathrm{delG}$, two harbour a null allele in combination with $\varepsilon 1369 \mathrm{delG}$, and one a null allele in combination with $\varepsilon$ R311Q (Table 1; Fig. 1). Strikingly, all patients harboured at least one copy of either $\&$ R311Q or $\varepsilon 1369 \mathrm{delG}$.

Haplotype analysis

To investigate the possibility that $\varepsilon \mathrm{R} 311 \mathrm{Q}$ and $\varepsilon 1369 \mathrm{delG}$ may be derived from original founder mutations we analysed a cluster of four single nucleotide polymorphisms (SNPs), rs1053754, rs8834, rs7774, rs9914357, that are 


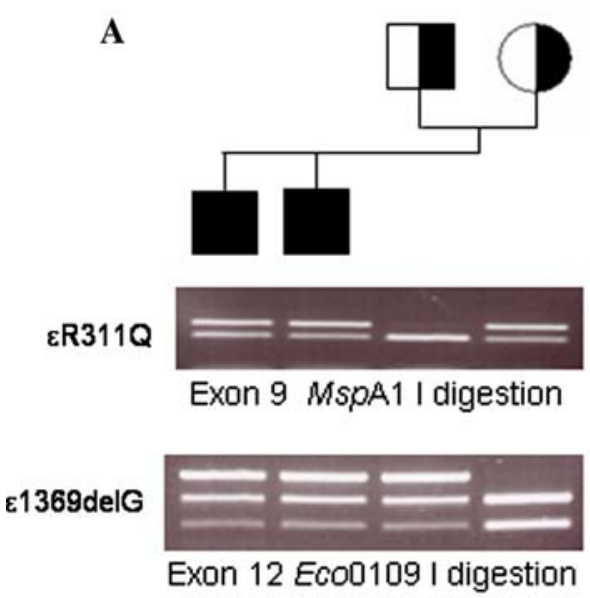

Fig. 1 a Restriction endonuclease digests of PCR amplicons of the AChR $\varepsilon$-subunit gene exons 9 and 12 amplified from genomic DNA. Affected individuals (shaded) in the kinship (patients 1 and 2) carry two mutant alleles, whereas members carrying one (half-shaded) are unaffected. b Example of SNP haplotypes within the $3^{\prime}$ untranslated

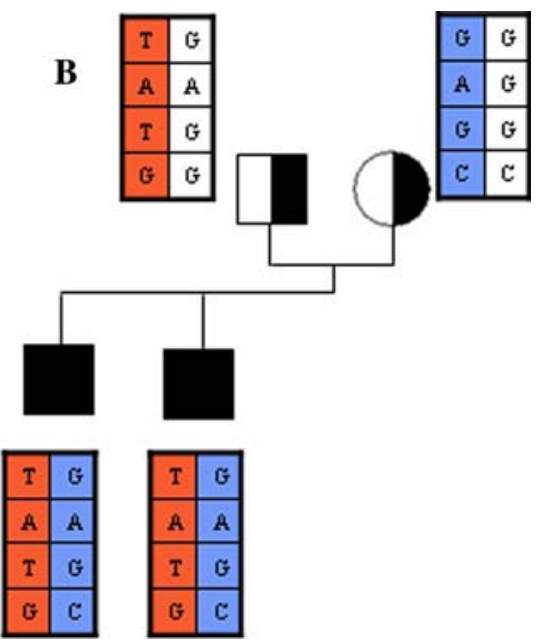

region of CHRNE showing the kinship containing patients 1 and 2, derived by DNA sequencing of genomic DNA from family members. Haplotype T A T G is seen to associate with the allele harbouring e1369delG and haplotype G A G C with the allele harbouring R311Q
Table 2 Analysis of SNPs clustered in $3^{\prime}$ untranslated region of CHRNE in Dutch patients with AChR deficiency syndrome

\begin{tabular}{lllllll}
\hline Patient & SNP & & & & \\
\cline { 2 - 6 } & rs1053754 & rs8834 & rs7774 & rs9914357 & Mutation & Mutation \\
\hline 1 & $\mathrm{~T} / \mathrm{G}$ & $\mathrm{A} / \mathrm{A}$ & $\mathrm{T} / \mathrm{G}$ & $\mathrm{G} / \mathrm{C}$ & 1369delG & R311Q \\
2 & $\mathrm{~T} / \mathrm{G}$ & $\mathrm{A} / \mathrm{A}$ & $\mathrm{T} / \mathrm{G}$ & $\mathrm{G} / \mathrm{C}$ & 1369delG & R311Q \\
3 & $\mathrm{~T} / \mathrm{T}$ & $\mathrm{A} / \mathrm{A}$ & $\mathrm{T} / \mathrm{T}$ & $\mathrm{G} / \mathrm{G}$ & 1369delG & 1369delG \\
4 & $\mathrm{~T} / \mathrm{G}$ & $\mathrm{A} / \mathrm{G}$ & $\mathrm{T} / \mathrm{T}$ & $\mathrm{G} / \mathrm{G}$ & 1369delG & 509insA \\
5 & $\mathrm{~T} / \mathrm{G}$ & $\mathrm{A} / \mathrm{A}$ & $\mathrm{T} / \mathrm{G}$ & $\mathrm{G} / \mathrm{C}$ & 1369delG & $\mathrm{R} 311 \mathrm{Q}$ \\
6 & $\mathrm{~T} / \mathrm{G}$ & $\mathrm{A} / \mathrm{A}$ & $\mathrm{T} / \mathrm{G}$ & $\mathrm{G} / \mathrm{C}$ & 1369delG & $\mathrm{R} 311 \mathrm{Q}$ \\
7 & $\mathrm{G} / \mathrm{G}$ & $\mathrm{A} / \mathrm{A}$ & $\mathrm{G} / \mathrm{G}$ & $\mathrm{C} / \mathrm{C}$ & $\mathrm{R} 311 \mathrm{Q}$ & $\mathrm{R} 311 \mathrm{Q}$ \\
8 & $\mathrm{~T} / \mathrm{G}$ & $\mathrm{A} / \mathrm{A}$ & $\mathrm{T} / \mathrm{G}$ & $\mathrm{G} / \mathrm{G}$ & 1369delG & Y15H \\
9 & $\mathrm{G} / \mathrm{G}$ & $\mathrm{A} / \mathrm{A}$ & $\mathrm{G} / \mathrm{G}$ & $\mathrm{G} / \mathrm{C}$ & $\mathrm{R} 64 \mathrm{X}$ & $\mathrm{R} 311 \mathrm{Q}$ \\
Heterozygosity & 0.471 & 0.385 & 0.481 & 0.455 & & \\
Frequency & $\mathrm{T} / \mathrm{G} 0.62 / 0.38$ & $\mathrm{~A} / \mathrm{G} 0.74 / 0.26$ & $\mathrm{~T} / \mathrm{G} 0.60 / 0.40$ & $\mathrm{G} / \mathrm{C} 0.65 / 0.35$ & & \\
\hline
\end{tabular}

located within the $3^{\prime}$ untranslated region of CHRNE. Haplotypes for patients and family members for the four SNPs were determined (Table 2; Fig. 1b). In all cases mutation $\varepsilon 1369$ delG associated with the haplotype T A T G at the four SNPs $(P=0.001)$ and mutation R311Q with SNP haplotype G A G C $(P=0.00006)$.

\section{Intercostal muscle biopsy}

Histological and electrophysiological characteristics of endplates from patients 4-7 are given in supplementary material. In patients 5 and 6 there was a reduction in the sensitivity of the endplates towards ACh and a decrease of the number of secondary synaptic clefts. However, in patients 4 and 7 the sensitivity of the endplates towards ACh was almost normal despite the clinical weakness, suggesting that in these patients the level of expression of the AChR $\gamma$ subunit is sufficient to effectively compensates for loss of the $\varepsilon$.

\section{Discussion}

To date, the Oxford Myasthenia Service has identified mutations that cause congenital myasthenic syndromes in 17 patients of Dutch origin. Four have mutations that cause slow channel syndrome, four have mutations in the RAPSN gene, and nine have mutations that underlie an AChR deficiency syndrome due to mutations within CHRNE. Mutation $\varepsilon 1369 \mathrm{delG}$ was present on at least one allele in seven of the nine $\varepsilon$-subunit gene AChR deficiency patients, and $\varepsilon$ R311Q in six. At Oxford the $\varepsilon 1369$ delG and $\varepsilon R 311 \mathrm{Q}$ 
mutations have not been identified in patients with CMS from other ethnic origins, but $81369 \mathrm{delG}$ has been reported in a patient from Northern Germany [10]. The common occurrence of $\varepsilon 1369 \mathrm{delG}$ and $\varepsilon \mathrm{R} 311 \mathrm{Q}$, and their strict association with the respective CHRNE SNP haplotypes (rs1053754-rs8834-rs7774-rs9914357: T A T G and G A G C) strongly suggests a founder for each of these mutations originating in North Western Europe, possibly in Holland.

Most CMS with severe endplate AChR deficiency result from recessive mutations in AChR $\varepsilon$-subunit gene, or the gene encoding rapsyn. The mutations in the $\varepsilon$-subunit are found along the length of the gene, and result in frameshifts or nonsense codons that truncate the subunit polypeptide chain, or loss of residues essential for AChR assembly or function. More than 90 different $\mathrm{AChR} \varepsilon$-subunit gene mutations have been described thus far [11, 12] (and D. Beeson, unpublished data).

Previous functional studies of the $\varepsilon 1369 \mathrm{delG}$ mutation, located close to the subunit $\mathrm{C}$-terminus, have shown that it is not incorporated into cell surface AChR and thus is a null allele $[9,10]$. Studies of $\varepsilon$ R311Q show that it is incorporated into surface AChR pentamers although at severely reduced levels, and in contrast to another mutation identified in the same site, $\measuredangle \mathrm{R} 311 \mathrm{~W}$ [13], does not affect AChR kinetics [9]. It is thought that patients harbouring homozygous or heteroallelic $\varepsilon$-subunit null mutations show partial phenotypic rescue through residual expression of the AChR $\gamma$-subunit $[7,13]$. Interestingly, symptoms in patient 3 , homozygous for ع1369delG, were not substantially more severe than in patients $1,2,5$ and 6 who are heteroallelic for $\varepsilon 1369 \mathrm{delG}$ and $\varepsilon \mathrm{R} 311 \mathrm{Q}$.

In many cases of AChR deficiency syndrome the kinship is found to have 'private' mutations and it may be necessary to screen the entire $\varepsilon$-subunit gene coding sequence. However, it is becoming clear that some $\varepsilon$-subunit gene mutations underlying AChR deficiency syndrome have an increased incidence in particular geographic regions, presumably arising from original founder mutations. The best examples of this are the 1293insG mutation arising in the Magreb population in North Africa, and in the Gypsy population of South Eastern Europe where $81267 \mathrm{delG}$ is common $[14,15]$. Here we highlight two mutations, $\varepsilon R 311 \mathrm{Q}$ and $\varepsilon 1369 \mathrm{delG}$, that are common in AChR deficiency syndrome patients of Dutch origin. Knowledge of the ethnic or geographic origin within Europe of AChR deficiency patients can help in targeting genetic screening, and our results suggest that for many patients of Dutch origin, screening first for $\varepsilon \mathrm{R} 311 \mathrm{Q}$ and $\varepsilon 1369 \mathrm{delG}$ may provide a rapid genetic diagnosis.

Acknowledgments We gratefully acknowledge support of the Prinses Beatrix Fonds (grant no MAR02-0204) to P. C.M. and support from the MRC and Myasthenia Gravis Association/Muscular Dystrophy Campaign to D.B.
Open Access This article is distributed under the terms of the Creative Commons Attribution Noncommercial License which permits any noncommercial use, distribution, and reproduction in any medium, provided the original author(s) and source are credited.

\section{References}

1. Engel AG, Ohno K, Sine SM (1994) Congenital myasthenic syndromes. In: Engel AG (ed) Myasthenia gravis and myasthenic disorders. Oxford University Press, New York

2. Beeson D, Newland C, Croxen R, Buckel A, Li FY, Larsson C et al (1998) Congenital myasthenic syndromes. Studies of the AChR and other candidate genes. Ann N Y Acad Sci 841:181183. doi:10.1111/j.1749-6632.1998.tb10924.x

3. Vincent A, Beeson D, Lang B (2000) Molecular targets for autoimmune and genetic disorders of neuromuscular transmission. Eur J Biochem 267(23):6717-6728. doi:10.1046/j.1432-1033. 2000.01785.x

4. Beeson D, Palace J, Vincent A (1997) Congenital myasthenic syndromes. Curr Opin Neurol 10(5):402-407. doi:10.1097/ 00019052-199710000-00008

5. Engel AG, Ohno K, Sine SM (1999) Congenital myasthenic syndromes: recent advances. Arch Neurol 56(2):163-167. doi: 10.1001/archneur.56.2.163

6. Engel AG, Ohno K, Sine SM (2003) Congenital myasthenic syndromes: progress over the past decade. Muscle Nerve 27(1):425. doi:10.1002/mus.10269

7. Croxen R, Young C, Slater C, Haslam S, Brydson M, Vincent A et al (2001) End-plate gamma- and epsilon-subunit mRNA levels in AChR deficiency syndrome due to epsilon-subunit null mutations. Brain 124(Pt 7):1362-1372. doi:10.1093/brain/124.7.1362

8. Oosterhuis HJGH (1997) Myasthenia gravis. Eight hundred patients with MG. Groningen Neurological Press, Groningen

9. Ealing J, Webster R, Brownlow S, Abdelgany A, Oosterhuis H, Muntoni F et al (2002) Mutations in congenital myasthenic syndromes reveal an epsilon subunit C-terminal cysteine, C470, crucial for maturation and surface expression of adult AChR. Hum Mol Genet 11(24):3087-3096. doi:10.1093/hmg/11.24.3087

10. Abicht A, Stucka R, Song IH, Karcagi V, Kugler K, BaumgartenWalczak A et al (2000) Genetic analysis of the entire AChR $\varepsilon$-subunit gene in 52 congenital myasthenic families. Acta Myologica 19:23-28

11. Beeson D, Hantai D, Lochmuller H, Engel AG (2005) 126th International Workshop: congenital myasthenic syndromes, 2426 September 2004, Naarden, the Netherlands. Neuromuscul Disord 15(7):498-512. doi:10.1016/j.nmd.2005.05.001

12. Engel AG, Sine SM (2005) Current understanding of congenital myasthenic syndromes. Curr Opin Pharmacol 5(3):308-321. doi: 10.1016/j.coph.2004.12.007

13. Ohno K, Quiram PA, Milone M, Wang HL, Harper MC, Pruitt JN 2nd et al (1997) Congenital myasthenic syndromes due to heteroallelic nonsense/missense mutations in the acetylcholine receptor epsilon subunit gene: identification and functional characterization of six new mutations. Hum Mol Genet 6(5):753766. doi: $10.1093 / \mathrm{hmg} / 6.5 .753$

14. Richard P, Gaudon K, Haddad H, Ammar AB, Genin E, Bauche $S$ et al (2008) The CHRNE 1293insG founder mutation is a frequent cause of congenital myasthenia in North Africa. Neurology 71(24):1967-1972. doi:10.1212/01.wnl.0000336921.51639.0b

15. Abicht A, Stucka R, Karcagi V, Herczegfalvi A, Horvath R, Mortier W et al (1999) A common mutation (epsilon1267delG) in congenital myasthenic patients of Gypsy ethnic origin. Neurology 53(7):1564-1569 